\title{
Management of non vital maxillary central incisors with open apex using Mineral Trioxide Aggregate apical plugs - Case report
}

\author{
Sumanthini M.V. ${ }^{1}$, Naisargi Shah ${ }^{2}$, Mausami A Malgaonkar ${ }^{3}$
}

\begin{abstract}
The case report describes the treatment of maxillary central incisors with open apex, due to apical root resorption, as a consequence of trauma experienced three years earlier. Open apices pose a challenge during endodontic treatment. Several materials and methods have been widely studied and tried in the past. Obtaining an adequate apical seal is of paramount importance regardless of the material or technique used. In the present case the involved teeth were treated nonsurgically using white Mineral Trioxide Aggregate (MTA) as an artificial apical barrier. The treated teeth were asymptomatic and the follow up clinical and radiographic examination showed healing with apparent regeneration of periradicular tissues. Extrusion of MTA beyond the root end was not an obstacle in the healing process. MTA can be considered an effective material to treat infected open apex teeth with large periapical lesions.
\end{abstract}

Key Words: Open apex, Periapical lesion, MTA, Non surgical method.

\section{Introduction}

Root canal treatment of teeth with open apices is challenging. Conventional root canal filling techniques rely considerably on the presence of apical constriction, against which gutta-percha can be optimally compacted. In the absence of apical constriction due to incomplete root formation, apical resorption or over instrumentation, inevitably there is extrusion of obturating material which could compromise the long term healing outcome of treatment. The treatment options have been either to induce apex formation or resort to surgical technique. Surgical method is more radical involving incision, flap reflection, root resection and root end filling placement, causing certain amount of discomfiture to patient. Traditionally long term calcium hydroxide $(\mathrm{CH})$ apexification has been used to induce apical closure and takes anywhere between 3-18 month ${ }^{1}$. Despite its high success rate it has

Professor ${ }^{1}$

Professor ${ }^{2}$

Lecturer $^{3}$

Department of Conservative dentistry and Endodontics MGM Dental College \& Hospital, Kamothe,

Navi Mumbai

Address for Correspondence:

Dr. Sumanthini M.V

Professor

Department of Conservative dentistry and Endodontics

MGM Dental College and Hospital, Kamothe, Navi Mumbai

Mob: 9869433642

Email: marg_suman@yahoo.com many drawbacks, namely patient compliance, multiple appointments, long drawn procedure, microleakage around provisional restorations, cervical fracture and reduction of fracture resistance of root structure $e^{2,3}$.

Various materials have been considered as an alternative to calcium hydroxide namely freeze dried alogenic dentin powder, bone ceramic, tricalcium phosphate, osteogenic protein, collgen, calcium gel and in particular MTA and Portland cement have been extensively evaluated in the recent past. White MTA (Proroot, Dentsply) is composed of bismuth oxide, tricalcium silicate, dicalcium silicate, calcium dialuminate and calcium sulphate dehydrated, trace elements like iron, nickel and copper, strontium ${ }^{4}$. The popularity of MTA for apical barrier technique can be attributed to its good sealing properties, excellent marginal adaptation, ability to set in the presence of moisture and the procedure can be completed in less number of visits. The biocompatibility and hard tissue inductive effect of MTA have been confirmed in animal and human studies ${ }^{5}$. Evidence from previous published reports support that MTA placement consistently resulted in regenerating normal periradicular tissues in teeth with immature apices and continued root maturation when pulpal necrosis was present ${ }^{6,7}$.

The following case report describes the non surgical management of non vital infected maxillary central incisors with open apices associated with a large periapical lesion in relation to 21 , secondary to trauma. 


\section{Case report}

A young lady aged 21 years was referred to outpatient clinic, Department of Conservative Dentistry and Endodontics with a chief complaint of continuous throbbing pain in relation to maxillary central incisors (11 and 21) since two days, discoloration and pus discharge from the palatal aspect, in relation to maxillary central incisors since one year (Fig.1). Patient gave a history of trauma 3 years ago. On examination, 11 showed discoloration and Ellis class 3 fracture involving mesial angle. While 21 had brownish discoloration. Both teeth were tender on percussion, with a sinus tract in the palatal aspect and non vital. The teeth 13,12,22 and 23 responded normally to vitality tests. Following clinical and radiological (Fig.2) examination a diagnosis of chronic periradicular abscess, with an acute exacerbation was made. Radiograph revealed apical root resorption with an open apex in both the teeth in question. Medical history was non contributory.

All treatment procedures were carried out under rubber dam isolation. Root canal access cavities were prepared in 11,21 and the canals were explored. Copious pus exuded through the canal of 21 . Both teeth

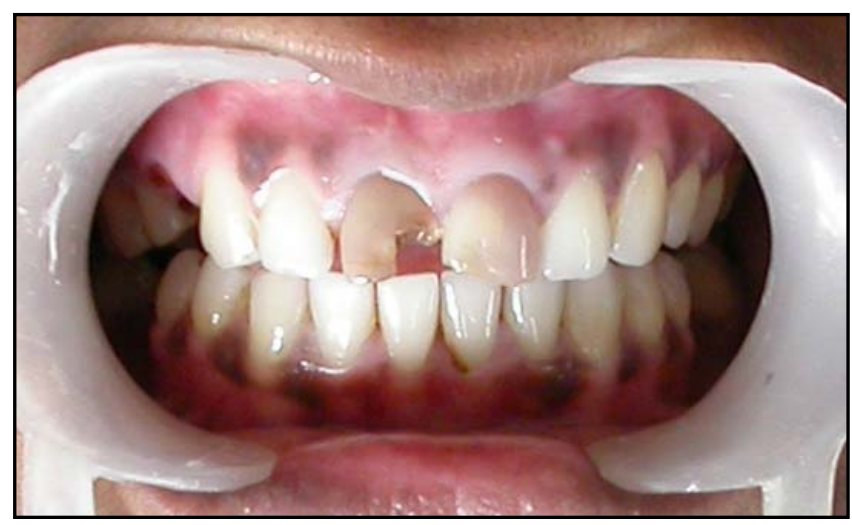

Fig. 1- Preoperative photograph showing mesial angle \# in 11, discoloration in $11,21$.

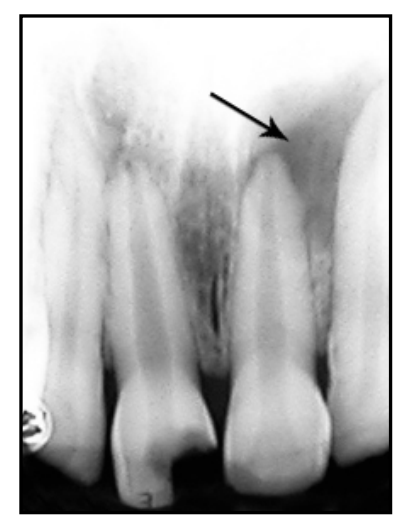

Fig. 2 - Preoperative radiograph, note the periapical lesion in 21 , indicated by the arrow.

had a single canal and no apical stop.An\#80 file(Mani,inc) could easily pass through the apical foramen without any resistance. Working length (Fig.3) was established using radiographic technique and canals irrigated with normal saline to encourage drainage. Canals were circumferentially filed and a thin paste of $\mathrm{CH}$ saline mix was placed in the canals and temporized with zinc oxide eugenol cement (Deepak Enterprise, Mumbai, India). Antibiotics and analgesics were prescribed. Patient was recalled the following day, her acute symptoms had subsided .When the canals were re-entered, slight discharge was noticed in 21. Canals were circumferentially filed, thoroughly irrigated intermittently with $5 \%$ sodium hypochlorite (Trifarma, Thane, India) $(5 \% \mathrm{NaOCl})$.A thick paste of extra pure calcium hydroxide(Deepashree Products, India) mixed with saline was placed in the canal and the access cavities were temporized with zinc oxide eugenol cement. The patient was recalled after a week and the same treatment regimen was repeated. A week hence the patient was asymptomatic and the sinus tract had resolved. The $\mathrm{CH}$ dressing was removed from 11, 21 and the canals were irrigated thoroughly with 5\% $\mathrm{NaOCl}$ followed by saline. Canals were dried with absorbent points. White MTA (Proroot, Dentsply) was mixed with sterile water as per manufacturer's instructions to thick putty like consistency. It was carried in to the canals with sterile amalgam carrier and condensed in to place with prefitted hand pluggers.An apical plug of $4 \mathrm{~mm}$ was placed in both 11 and 21(Fig.4); a radiograph was taken to confirm the dense packing of MTA. A moist cotton pledget was placed in the canal to aid in setting and the teeth were temporized with zinc oxide eugenol cement. Patient was recalled the following day and remaining canal portion was obturated with guttapercha (Dentsply Maillefer) and AH Plus (Dentsply) root canal sealer (Fig.5). Finally the teeth were

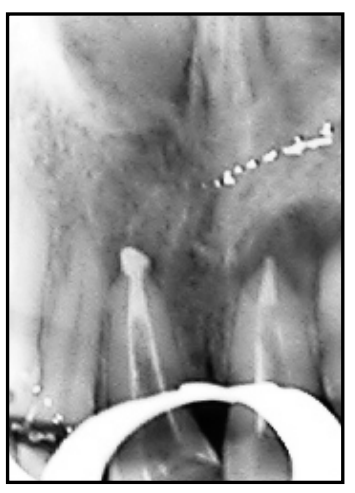

Fig. 4 - Radiograph showing MTA apical plug placement in 11 and 21.

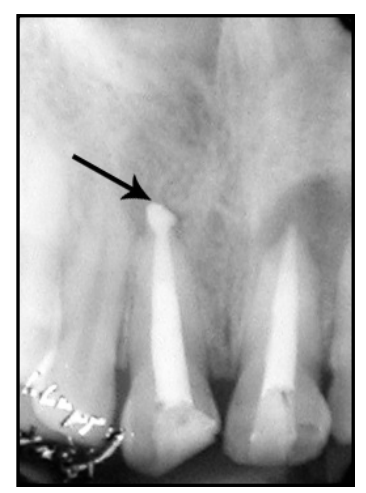

Fig. 5 - Radiograph showing obturation of 11 and 21 note the extrusion of MTA indicated by the arrow. 
restored with resin composite in both the access cavities followed by metal ceramic crowns (Fig.6, 7). Patient was recalled for regular checkups to follow the treatment out come at regular time intervals, (Fig.8, 9) and further long term follow-up.

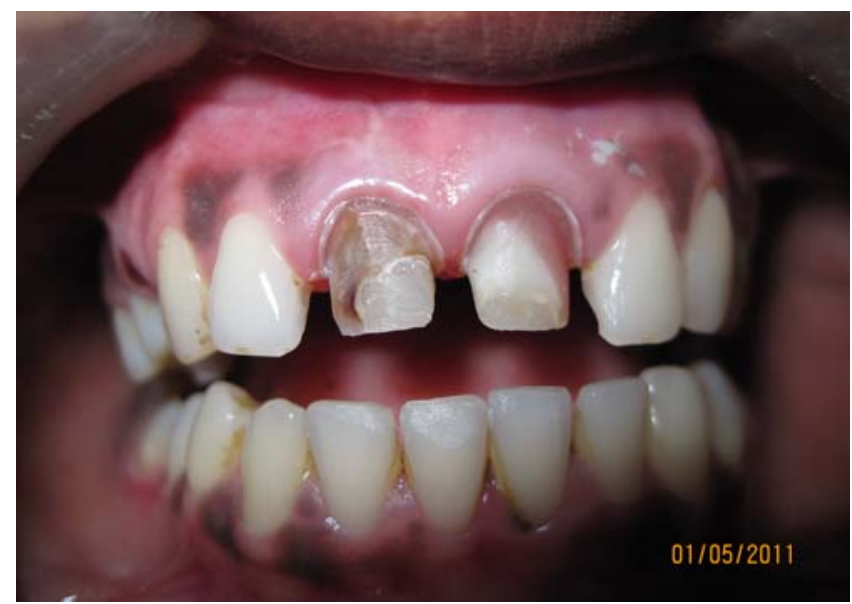

Fig. 6 - Photograph showing tooth preparation done in 11, 21.

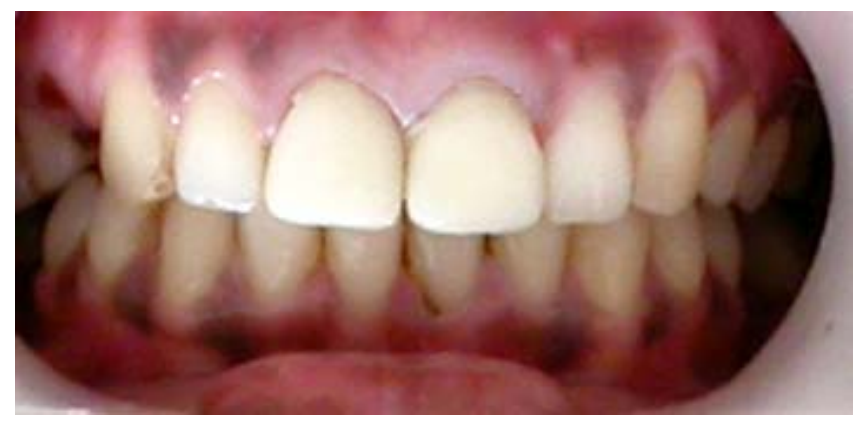

Fig. 7 - Photograph showing 11, 21 restored with metal ceramic crowns.

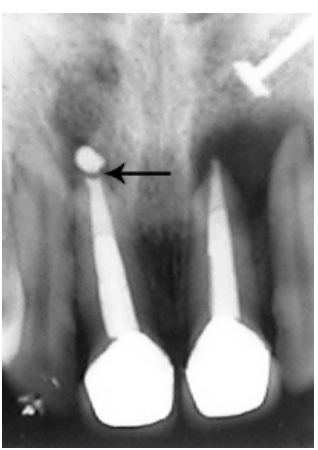

Fig. 8 - Three month follow up radiograph showing hard tissue deposition over MTA surface indicated by the arrow and extruded MTA surrounded by osseous tissue.

\section{Discussion}

Traumatic injury to mature teeth results in pulp necrosis due to periapical neurovascular supply damage .When injury damages the protective layer of precementum, inflammation of pulp or periodontium will induce resorption in root and bone as the microbial toxins can pass through the dentinal tubules and stimulate an inflammatory response. In the present case, the maxillary central incisors had open apices caused due to apical root resorption and chronic apical abscess in 11 and 21 respectively as a result of trauma induced apical periodontitis and pulp necrosis. The objective here is to control infection and induce apical closure. $\mathrm{CH}$ as an intracanal dressing has been the most widely used and clinically accepted for over 40 years. Recent research evidence has demonstrated that the long term calcium hydroxide apexification treatment, significantly reduces the fracture resistance of the $\operatorname{tooth}^{3}$.This is attributed to decreased organic support of dentin matrix leading to disruption of the bond between the collagen fibrils and hydroxyapatite crystals that negatively influence the mechanical properties of dentin. In the present case calcium hydroxide was used for a short duration as an intracanal medicament since it is known to significantly reduce the endodontic micro flora without compromising the fracture resistance of dentin. Calcium hydroxide when placed for not more than 30 days does not cause any deleterious effect on dentin ${ }^{2}$. Bidar etal found in their study that medication with calcium hydroxide improved the marginal adaptation of MTA $^{8}$. Shabahang et al in their animal studies demonstrated a more predictable healing outcome when MTA is used to obturate open apex teeth when compared with teeth treated with calcium hydroxide ${ }^{9}$.MTA represents a contemporary version of the primary monoblock in attempts to strengthen immature tooth roots. Although MTA does not bond to dentin interaction of the released calcium and hydroxyl ions of MTA with a phosphate containing synthetic body fluid results in formation of apatite like interfacial deposits. These deposits improve the frictional resistance of MTA to the root canal walls and accounts for the seal of MTA in orthograde obturation and perforation repair ${ }^{10}$.

Following the calcium hydroxide medication the patient was asymptomatic and there was cessation of pus discharge from the canal. A $4 \mathrm{~mm}$ MTA apical plug was placed in both the incisor teeth. Invitro studies have suggested that a 4-5mm of MTA plug is sufficient to provide an adequate seal. This is also supported by retrospective studies under taken to evaluate the treatment outcomes of artificial apical barrier with MTA in teeth with immature apices 11,12 . The biocompatibility of MTA is well documented. It promotes the formation of cementum coverage over 
the MTA surface with a high degree of structural integrity and more complete periradicular architecture. The production of bone morphogenetic protein-2 (BMP-2) AND transforming growth factor -beta-1 (TGF- $\beta$-1) could be instrumental for the favorable biologic response stimulated in human periapical tissues ${ }^{13}$. The stimulation of interleukin production causes the cementum overgrowth. The above factors collectively facilitates regeneration of periodontal ligament and formation of bone.

In the present case no attempt was made to place an internal matrix at the apex in order to retain the MTA within the confines of the root canal space ${ }^{14}$. Absence of apical constriction led to extrusion of MTA beyond the root apex. The extruded MTA (Fig.8) was separated from the root end and was surrounded by normal bone.The follow up radiographs showed the gradual resorption of the extruded material. Despite the extrusion healing of the periapical lesion was uneventful. There was regeneration of periradicular tissue, normal periodontal space, decrease in size of periapical lesion as compared with preoperative radiograph and no evidence of inflammatory external root resorption(Fig. 8,9). This corroborates with the retrospective study of Zafer et al and Johannes Mende et al that the healing outcome of teeth was unaffected by extrusion of $\mathrm{MTA}^{6,15}$.

\section{Summary}

The present case report confirms that MTA acts as an apical barrier and can be effectively used to support regeneration of periapical tissue in traumatized infected teeth with open apices, involving large periapical lesions. Both clinical and radiographic follow ups revealed optimal healing of the periapical lesion and new hard tissue formation in the apical area of the traumatized incisors in spite of extrusion of MTA. Hence it can be concluded that MTA plugs predictably induce apical closure in shorter treatment time and without much dependence on patient compliance.

\section{References}

1. John I. Ingle, Lief K Bakland, J. Craig Baumgartner, Ingle's Endodontics $6^{\text {th }}$ edition. page- 1337 .

2. Andreasen JO, Munksgaard EC, Bakland LK. Comparison of fracture resistance in root canals of immature sheep teeth after filling with calcium hydroxide or MTA. Dent Traumatol 2006;22:154-6.

3. Glen .E. Doyon, Thom Dhumsha, J Anthony von Fraunhofer. Fracture resistance of human root dentin exposed to intracanal calcium hydroxide. J Endod 2005;31:895-897.

4. Araceli I, Bucio L, Cruz-chwez E. Phase composition of Proroot MTA by x-ray powder diffraction. J Endod 2009;35:875-878.

5. N.K. Sarkar, R.Caicedo, P.Ritwik, R. Moiseyeva, I. Kawashima. Physicochemical basis of biologic properties of mineral trioxide aggregate Endod 2005; 31:97-100.

6. Zafer C. Cehreli, Sezgi Sara, Serdar Uysal, Melek D Turgut. MTA apical plugs in the treatment of traumatized immature teeth with large periapical lesions. Dent Traumatol 2011; 27:59-62.

7. Holden DT Schwartz SA Kirkpatrick TC, Schindler WG. Clinical outcomes of artificial root barriers with mineral trioxide aggregate in teeth with immature apices ENDOD 2008;34:812-7.

8. Maryam Bidar, Reza Disfani, Salman Ghargozloo, Shirin Khoynezhad and Armita Rouhani.J Endod 2010; 36:16791682.

9. Shabahang S, Torabenajed M, Boyne PP, Abedi H,McMillan P. A comparative study of root end induction using osteogenic protein-1, calcium hydroxide and mineral trioxide aggregate in dogs Endod 1999;25:1-5.

10. Franklin R .Tay, David H Pashley. Monoblocks in root canals: A hypothetical or a tangible goal. J Endod 2007;33:391398.

11. David E Witherspoon, Joel C Small, John D Regan, Martha Nunn. Retrospective analysis of open apex teeth obturated with MTA.J Endod 2008; 34:1171-1176.

12. Ahmed AL Kahtani, Sandra Shostad, Roebrt Schifferte, Stish Bambhani. Invitro evaluation of microleakage of an orthograde apical plug of MTA in permanent teeth with simulated immature apices. J Endod 2005; 31:117-119.

13. Gunseli Gunsen, Zafer C Cehreli, Ali Ural, Muhittin A Sedar, Feridun Basak. Effect of MTA cement on Transforming Growth factor ?-1 and Bone Morphogenic Protien production by human fibroblasts invitro.J Endod 2007;33:447-450.

14. C. Bargholz.Perforation repair with mineral trioxide aggregate modified matrix concept.Int Endod J 2005;38:5969.

15. Johannes Mente, Nathalie Hage,Thorsten Pfefferle, Martin J ean Koch, Jens Dreyhaupt, Hans Joerg Staele, Shimon Friedmann. Mineral trioxide aggregate apical plugs in teeth with open apical foramina :A retrospective analysis of treatment outcome.J Endod 2009;35:1354-1358. 